Article

\title{
An Overview on Acute Malnutrition and Food Insecurity among Children during the Conflict in Yemen
}

\author{
Fekri Dureab ${ }^{1,2, *}$ (), Eshraq Al-Falahi ${ }^{3}$, Osan Ismail ${ }^{3}$, Lina Al-Marhali ${ }^{1}$, Ayoub Al Jawaldeh ${ }^{4}$, \\ Nazmun Nahar Nuri ${ }^{2}$, Elvis Safary ${ }^{2}$ and Albrecht Jahn ${ }^{2}$ \\ 1 Modern Social Association (MSA), Aden, Yemen; almarhalilina@gmail.com \\ 2 Heidelberg Institute of Global Health, Hospital University, Heidelberg 69115, Germany; \\ nuri.nazmun-nahar@uni-heidelberg.de (N.N.N.); elvisafary@gmail.com (E.S.); \\ Albrecht.Jahn@uni-heidelberg.de (A.J.) \\ 3 World Health Organization (WHO), P.O. Box 543, Sana'a, Yemen; alfalahie@who.int (E.A.-F.); \\ ismailo@who.int (O.I.) \\ 4 World Health Organization, EMRO, P.O. Box 7608, Nasr City, Cairo 11371, Egypt; aljawaldeha@who.int \\ * Correspondence: fekridureab@yahoo.com; Tel.: +49-17620084242
}

Received: 11 May 2019; Accepted: 31 May 2019; Published: 5 June 2019

\begin{abstract}
Background: This study aims to describe malnutrition among children under five and to describe the food insecurity status during the current conflict in Yemen. Methods: Data were obtained from a Yemeni nutrition surveillance program (pilot phase) targeting 4142 households with 5276 children under five from two governorates (Ibb and Sana'a). Results: Global acute malnutrition was found in $13.3 \%$ of overall screened children, while $4.9 \%$ had severe acute malnutrition (SAM) and $8.4 \%$ had moderate acute malnutrition. One-fifth of the children under six months of age were acutely malnourished, followed by children under two years at $18.5 \%$ based on weight-for-height $\mathrm{z}$ scores. Significant associations between malnutrition and other diseases included suspected measles at three times higher rates $(4.5 \%, p<0.00)$ among SAM cases than other children. Diarrhea, fever, and cough were significantly higher among the SAM group $(p<0.05)$. Most households depended on market food purchases in the month preceding this survey (84.7\%). Household coping mechanisms to secure daily meals included borrowing food to survive, changing types and quality of food, and decreasing the number of meals per day; some families sent their children to live with relatives. Conclusion: Malnutrition is a serious public health problem. The humanitarian community needs to adopt alternative strategies to improve food security and the nutrition status in Yemen.
\end{abstract}

Keywords: malnutrition; food insecurity; infection; Yemen

\section{Introduction}

Yemen is the poorest country in the Middle East and North Africa, and since March 2015 it has been facing a significant humanitarian and security crisis. The ongoing intensified war and disrupted social services have had a clear impact on the general health and nutrition status of the children and entire population [1]. The food distribution mechanism in the country has been severely disturbed. Yemen is highly dependent on imported food, and the current armed conflict has blocked food transportation, which has caused a food crisis. The decrease in food availability has led to an increase in food costs, although the conflict has devastated purchasing power as a result of increased unemployment and loss of family incomes [2,3].

Yemen is facing the largest food security emergency in the world because of a severe decline in agriculture production, which affects approximately $60 \%$ of Yemenis who depend on agriculture 
for their livelihoods [4]. According to the Integrated Food Security Phase Classification (IPC), 13 of 22 governorates are experiencing catastrophic conditions (IPC phase 5), 17\% of the population (5 million) are classified in an emergency phase (IPC phase 4), and 36\% (approximately 10.8 million) are in a crisis phase (IPC phase 3) [5]. Yemen has one of the highest rates of chronic malnutrition, with estimates of stunting in $47 \%$ of children under five and wasting in 15\% [6].

The United Nations (UN) has estimated that 22.2 million people in Yemen need some kind of humanitarian assistance. The UN report also notes that approximately 17.8 million are food insecure and 16.4 million lack adequate healthcare. A total of 1.8 million children are acutely malnourished, and 462,000 children suffer from severe acute malnutrition (SAM) [7]. Conflict is driving people from their homes at alarming rates since an estimated 2 million people are currently displaced within Yemen [8]. Since there are no camps for internally displaced persons (IDPs), displacement has led to a dispersed population that is often difficult to identify or assess for vulnerability or specific needs. Prior to the conflict's escalation in March 2015, significant humanitarian needs already existed across Yemen [9]. In Hodeida, approximately 100,000 children under the age of five are at risk for SAM compared to 23,000 before 2015. In Aden, the figure more than doubled and is currently 7700 compared to 3000 before 2015 [10].

The most common diseases associated with acute malnutrition are respiratory infections. Pneumonia is common in malnourished children and leads to fatal complications [11]. Pneumonia and diarrheal diseases account for approximately $27 \%$ of the mortality of children under five in Yemen [12]. Globally, malnutrition is responsible for nearly half $(45 \%)$ of all deaths of children under the age of five [13]. Together with poor diet, malnutrition is the number one driver of the global burden of disease. According to WHO, 5.9 million children worldwide died under the age of five in 2015, although the deaths were due to preventable and curable conditions if the children had access to simple, affordable interventions [13].

This study aims to determine the prevalence and factors associated with acute malnutrition among children under five years in the communities of Ibb and Sana'a governorates during the current conflict in Yemen.

\section{Materials and Methods}

This study analyzed data that were obtained from the Yemeni nutrition surveillance program. The nutrition surveillance system is an active, population-based surveillance, started as a pilot in two governorates (Ibb and Sana'a). The survey was conducted by 88 trained field investigators, distributed over 18 districts in 234 clusters (villages). The total study population included 4142 households and a total of 5276 children under five years old. The survey was conducted by health staff from health facilities in the same districts. Several variables in nutrition and health were used in this study, Table 1 shows definitions of some variables.

Table 1. Definitions.

\begin{tabular}{cc}
\hline Variable & Definition \\
\hline Exclusively breastfed & $\begin{array}{c}\text { The infant under six months was only breastfed. No other liquids } \\
\text { (even water) or solids were given, with the exception of medicine. }\end{array}$ \\
\hline Breastfeeding during the survey & The child was still breastfed up to the age of two \\
\hline Suspected measles & $\begin{array}{c}\text { The child was suffering from fever, rash, and cough and/or } \\
\text { conjunctivitis, and they were diagnosed clinically as suspected } \\
\text { measles by medical staff in a health facility. }\end{array}$ \\
\hline Diarrheal & Passage of three or more loose stools per day \\
\hline Fever & Temperature identified by mothers above the normal (subjective) \\
\hline Vaccination status & $\begin{array}{c}\text { If child had all vaccinations or some of them (BCG for TB, OPV for } \\
\text { Polio, Pentavalent, Rotavirus C, and MCV for Measles) }\end{array}$ \\
\hline
\end{tabular}


Sampling was stratified by administrative units and samples among clusters of geographic units (villages, urban segments, or statistical enumeration areas). The surveillance design had three stages of sampling (cluster-household-respondent). Probability proportional to size (PPS) sampling was the primary methodology for selecting clusters, while random sampling was used at the household level.

Data were analyzed using Emergency Nutrition Assessment (ENA) software and SPSS version 25 (IBM Corp., Armonk, NY, USA). Outcomes were compared between the two governorates. Chi-square tests were applied to examine the association between malnutrition and associated health factors. Furthermore, logistic regression was applied to examine the effects of malnutrition on the children's general health status. The result of the regression analysis was presented by odds ratios (ORs) with 95\% confidence intervals (CIs).

\section{Ethical Consideration}

An official approval was obtained from the Ministry of Public Health and World Health Organization in Yemen to use these data for further analysis.

\section{Results}

The total study population of children was 5276. Approximately $52.6 \%$ of the children were male. One-third of the children were under two years old; mean age was 31.25 months ( $\mathrm{SD} \pm 16.56$ ), mean height was $82.61 \mathrm{~cm}(\mathrm{SD} \pm 12.90)$, and mean weight was $10.63 \mathrm{~kg}(\mathrm{SD} \pm 3.10)$ (see Table 2).

Table 2. Demographic characteristics of children under five in Ibb and Sana'a governorates.

\begin{tabular}{cccc}
\hline \multirow{2}{*}{ Characteristics } & \multicolumn{2}{c}{ Children } \\
\cline { 3 - 4 } & & Number & Percentage \\
\hline \multirow{2}{*}{ Governorate } & Sana'a & 2368 & $45 \%$ \\
& Ibb & 2908 & $55 \%$ \\
\hline \multirow{2}{*}{ Sex } & Male & 2777 & $52.6 \%$ \\
& Female & 2499 & $47.4 \%$ \\
\hline \multirow{3}{*}{ Age group } & $>6$ months & 270 & $5.1 \%$ \\
& $6-23$ months & 1522 & $28.8 \%$ \\
& $24-59$ months & 3484 & $66 \%$ \\
\hline
\end{tabular}

The total number of acutely malnourished children according to weight-for-height z scores (WHZ) was 706 of the total 5276. Global acute malnutrition (GAM) was found in 13.3\% of all screened cases, while $4.9 \%$ had SAM and $8.4 \%$ had moderate acute malnutrition.

Children under six months are the most affected by acute malnutrition. Table 3 shows that $20 \%$ of the children under six months in Ibb and Sana'a were acutely malnourished, followed by children under two years of age (18.5\%) based on WHZ.

Table 3. Distribution of the nutritional status of children under five years of age in Ibb and Sana'a governorates by MUAC * and $\mathrm{WHZ}^{* *}$ according to age group.

\begin{tabular}{|c|c|c|c|c|c|c|}
\hline \multirow[t]{2}{*}{ Classification. } & \multicolumn{2}{|c|}{$\begin{array}{l}\text { Moderate Acute } \\
\text { Malnutrition }\end{array}$} & \multicolumn{2}{|c|}{ Severe Acute Malnutrition } & \multicolumn{2}{|c|}{ Global Acute Malnutrition } \\
\hline & WHZ & MUAC & WHZ & MUAC & WHZ & MUAC \\
\hline$<6$ months & $23(8.5 \%)$ & & $31(11.5 \%)$ & & $54(20 \%)$ & \\
\hline 6-23 months & $175(11.5 \%)$ & $267(17.5 \%)$ & $106(7 \%)$ & $189(12.4 \%)$ & $281(18.5 \%)$ & $456(29.9 \%)$ \\
\hline 24-59 months & $247(7 \%)$ & $286(8.8 \%)$ & $120(3.4 \%)$ & $122(3.5 \%)$ & 367 (10.5\%) & $408(11.6 \%)$ \\
\hline Total & $445(8.4 \%)$ & $600(11.3 \%)$ & $257(4.9 \%)$ & $337(6.3 \%)$ & $702(13.3 \%)$ & 937 (17.6\%) \\
\hline
\end{tabular}

${ }^{*}$ MUAC, mean upper arm circumference; ${ }^{* *} \mathrm{WHZ}$, weight-for-height $\mathrm{z}$ score. 
There are many factors that affect the nutritional status of children in Yemen, and Table 4 provides examples. Approximately $43 \%$ of the children under six months were still exclusively breastfed during the survey in both governorates (55\% in Ibb and 33\% in Sana'a). The majority of children had been vaccinated completely or partially in Ibb (93.9\%) and Sana'a (92\%), although $1.7 \%$ of children in Ibb and $1.4 \%$ in Sana'a had a history of suspected measles in the week prior to the survey. Diarrhea, fever, and cough were common in both governorates: $27.4 \%, 30.7 \%$, and $29.3 \%$, respectively, in Ibb and $25.1 \%, 31.3 \%$, and $33.2 \%$, respectively, in Sana'a.

Table 4. Factors affecting the nutritional status of the targeted children under five years of age in Ibb and Sana'a governorates.

\begin{tabular}{cccccc}
\hline \multirow{2}{*}{ Health Factors } & & \multicolumn{2}{c}{ Ibb } & \multicolumn{2}{c}{ Sana'a } \\
\cline { 3 - 6 } & & $\mathbf{N}$ & $\%$ & $\mathbf{N}$ & $\%$ \\
\hline Exclusively breastfed children & Yes & 61.0 & $55 \%$ & 44.0 & $33 \%$ \\
under six months & No & 50.0 & $45 \%$ & 89.0 & $67 \%$ \\
\hline Breastfeeding during the & Yes & 704.0 & $24.2 \%$ & 559.0 & $23.6 \%$ \\
survey time & No & 2214.0 & $74.8 \%$ & 1814.0 & $76.4 \%$ \\
\hline Suspected measles history in & Yes & 49.0 & $2 \%$ & 33.0 & $1.4 \%$ \\
the week prior the survey & No & 2871.0 & $98 \%$ & 2340.0 & $98.6 \%$ \\
\hline Diarrheal history in the week & Yes & 800.0 & $31.8 \%$ & 596.0 & $25 \%$ \\
prior the survey & No & 2121.0 & $68.2 \%$ & 1777.0 & $75 \%$ \\
\hline Fever history in the week & Yes & 897.0 & $35.3 \%$ & 742.0 & $31.3 \%$ \\
prior the survey & No & 1644.0 & $64.7 \%$ & 16310 & $68.7 \%$ \\
\hline Cough history in the week & Yes & 856.0 & $33.5 \%$ & 788.0. & $33.2 \%$ \\
prior the survey & No & 1703.0 & $66.5 \%$ & 1585.0 & $66.8 \%$ \\
\hline Vaccination status & Yes & 2449.0 & $93.9 \%$ & 2029.0 & $92 \%$ \\
& No & 82.0 & $3.1 \%$ & 102.0 & $4.6 \%$ \\
& Unknown & 77.0 & $3.0 \%$ & 76.0 & $3.4 \%$ \\
\hline
\end{tabular}

Table 5 shows associations of the most common health problems and malnutrition in children under five years old. There were significant associations between malnutrition and other diseases. For instance, suspected measles was three times higher $(4.5 \%, p<0.00)$ among SAM cases than other children. Similarly, diarrhea (38\%), fever $(37.7 \%)$, and cough $(38.6 \%)$ were significantly higher among children with SAM than other children $(p<0.05)$.

Table 5. Associations between health problems and the nutritional status of children under five years of age in the targeted areas of Ibb and Sana'a governorates.

\begin{tabular}{|c|c|c|c|c|c|c|c|c|}
\hline \multirow{2}{*}{\multicolumn{2}{|c|}{$\begin{array}{l}\text { Health Factors-History of Disease } \\
\text { in the Week Prior to Survey }\end{array}$}} & \multicolumn{2}{|c|}{$\begin{array}{c}\text { Adequate } \\
\text { Nutritional Status }\end{array}$} & \multicolumn{2}{|c|}{$\begin{array}{l}\text { Moderate Acute } \\
\text { Malnutrition }\end{array}$} & \multicolumn{2}{|c|}{$\begin{array}{l}\text { Severe Acute } \\
\text { Malnutrition }\end{array}$} & \multirow[t]{2}{*}{$\begin{array}{c}p \text {-Value } \\
\text { Chi-Square }\end{array}$} \\
\hline & & $\mathbf{N}$ & $\%$ & $\mathbf{N}$ & $\%$ & $\mathbf{N}$ & $\%$ & \\
\hline \multirow{2}{*}{ suspected measles } & Yes & 60 & $1.4 \%$ & 7 & $1.2 \%$ & 15 & $4.5 \%$ & \multirow{2}{*}{$p<0.000$} \\
\hline & No & 4305 & $98.6 \%$ & 584 & $98.8 \%$ & 322 & 95.5 & \\
\hline \multirow{2}{*}{ Diarrhea } & Yes & 1105 & $25.3 \%$ & 162 & $27.4 \%$ & 128 & $38 \%$ & \multirow{2}{*}{$p<0.000$} \\
\hline & No & 3260 & $74.7 \%$ & 429 & $72.6 \%$ & 209 & $62 \%$ & \\
\hline \multirow{2}{*}{ Fever } & Yes & 1337 & $30.6 \%$ & 180 & $30.5 \%$ & 127 & $37.7 \%$ & \multirow{2}{*}{$p<0.025$} \\
\hline & No & 3028 & $69.4 \%$ & 411 & $69.5 \%$ & 210 & $62.3 \%$ & \\
\hline \multirow{2}{*}{ Cough } & Yes & 1320 & $30.2 \%$ & 189 & $32.0 \%$ & 130 & 38.6 & \multirow{2}{*}{$p<0.005$} \\
\hline & No & 3045 & 69.8 & 402 & $68.0 \%$ & 207 & $61.4 \%$ & \\
\hline
\end{tabular}

\section{Food Security at the Household Level}

The mean number of household members was 7.5 persons $(\mathrm{SD} \pm 3.922)$, and the mean number of children under five years old was 1.34 children $(\mathrm{SD} \pm 1.166)$. The mean daily meals for children under two years was 1.37 meals $(\mathrm{SD} \pm 1.876)$ and was 2.09 meals $(\mathrm{SD}+1.843)$ for those $24-59$ months. 
Table 6 shows that families had various sources of food, and most depended on purchasing food from the market in the month preceding this survey $(84.7 \%)$. Families in the Sana'a governorate depended more on food purchasing than those in Ibb. Agriculture was the second source of food overall (30.5\%). Receiving food from humanitarian assistance was the third most common source overall (10.9\%), comprising $16.6 \%$ in Sana'a governorate and 5.7\% in Ibb.

Table 6. Distribution of food sources among families in the target communities in Ibb and Sana'a by governorate (multiple answers possible).

\begin{tabular}{cccc}
\hline Source of Family Food & Ibb N (\%) & Sana'a N (\%) & Total N (\%) \\
\hline Agriculture & $715(32.1 \%)$ & $582(28.9 \%)$ & $1297(30.5 \%)$ \\
Market & $1848(83 \%)$ & $1743(86.6 \%)$ & $3591(84.7 \%)$ \\
Humanitarian Assistance & $127(5.7 \%)$ & $334(16.6 \%)$ & $461(10.9 \%)$ \\
\hline
\end{tabular}

Figure 1 shows that families in the targeted communities used various coping mechanisms to secure daily meals. Approximately $40 \%$ of the families borrowed food to survive $(46 \%$ in $\mathrm{Ibb}$ and $33.4 \%$ in Sana'a). One-quarter of the families changed the type and quality of their food to mitigate household food shortages (30\% in Ibb and 23\% in Sana'a). Decreasing the number of meals was also an option for $10.8 \%$ of poor families overall, comprising $8.5 \%$ in Ibb and $13.3 \%$ in Sana'a. Other families sent their children to live with relatives to reduce the number of people in the household: $3.3 \%$ in Ibb and $5.7 \%$ in Sana'a.

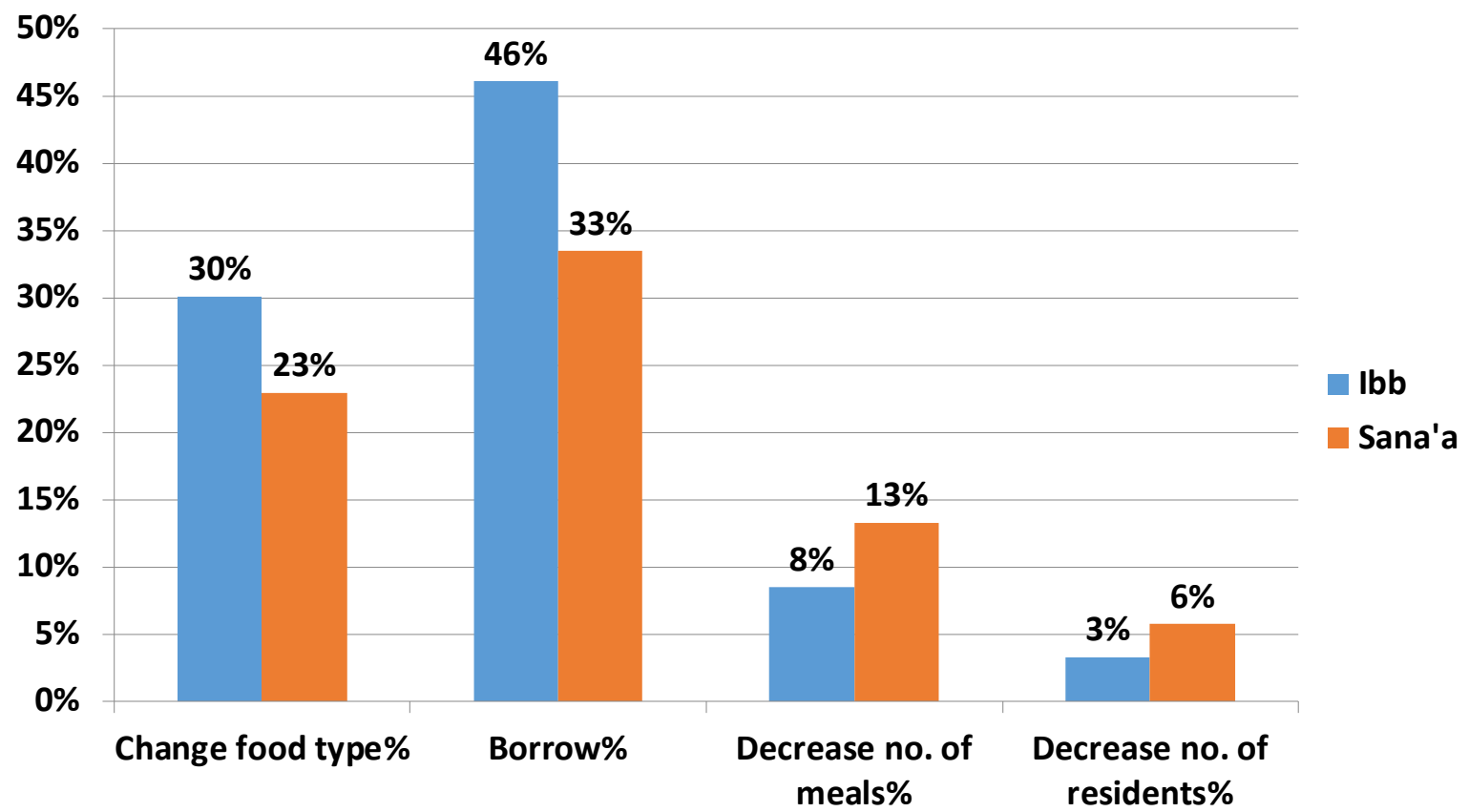

Figure 1. Distribution of coping mechanisms for food insecurity among families in the target communities of Ibb and Sana'a by governorate (multiple answers possible).

\section{Discussion}

GAM for both Ibb and Sana'a governorates was 13.3\% (WHZ). This high prevalence of acute malnutrition is classified as a critical phase, although it does not exceed the emergency threshold $15 \%$ [14]. The national rate of GAM for Yemen was 16\% in the last demographic health survey (DHS) in 2013 [6]. However, the Nutrition Cluster report (SMART) in April 2017 showed that the GAM rates in both governorates were classified as poor (between $5 \%$ to $9.99 \%$ ) [15]. The difference in GAM rates between this survey and SMART 2017 could be due to seasonal differences that made comparisons invalid or the seasonal impact of nutrition interventions in both governorates. 
The SMART and Yemen Emergency Food Security and Nutrition Assessment (EFSNA) surveys in Ibb and Sana'a did not indicate a major deterioration in the prevalence of GAM compared to levels before March 2015 (preconflict) [16-18]. However, food security surveys indicated an obvious deterioration in the outcomes in Ibb and Sana'a governorates [19]. In 2017, IPC indicated that the deterioration had increased by $20 \%$ compared to the results of IPC 2016 [5]. Despite the ongoing conflict and deterioration of the economic situation in Yemen, IPC 2018 showed an improvement in food security by $7 \%$ compared to 2017 . On the negative side, the same report showed that $0.2 \%$ of the population $(63,500)$ was in a catastrophic phase of food insecurity (IPC phase 5) [20], thus an impact study was recommended after more than three years of humanitarian work in Yemen.

The severity of acute malnutrition decreases with the children's increasing age. The prevalence of acute malnutrition among children under two years was much higher than children 24-59 months. This finding is in line with studies in India that also report a high prevalence of malnutrition among children under two years old [21,22]. This clearly indicates a relationship between malnutrition and the practice of infant and young child feeding in these communities; this age is a period for physical growth and an increase in metabolic demands. Therefore, more energy and nutrients, more than what is provided by breast milk and complementary feeding, are needed [23]. The practice of breast feeding is low in these communities-only $24 \%$ of the children under two years were still breastfed during the study period in Yemen. On the other hand, SMART 2017 in Ibb found that $63 \%$ of the children were still breastfed, and similar results were found in Sana'a (67\%) in the SMART 2016 report. Several studies showed that improper feeding practices of young children were associated with malnutrition in poor communities [22,24]. This Yemeni study revealed that the mean number of meals taken by the children per day was very low: 1.37 meals for children between 6-23 months and 2.09 meals for children of age $24-59$ months.

Morbidity is more common among malnourished children. In this Yemeni study, $31 \%$ of the children under five had complained of fever within the week preceding the survey in both governorates. This finding was close to the level of fever prevalence reported in the 2013 DHS (32\%). The prevalence of diarrhea was $26.5 \%$ among children within the week preceding the survey, which was less than the national prevalence in the DHS 2013 report (31\%). A history of cough and acute respiratory infection (ARI) among children under five within the week preceding the survey was $31 \%$ in both governorates, while in DHS 2013 it had been 12\%; however, rates of ARI were high in SMART surveys of Ibb 2017 and Sana'a 2016 (42\% and 50\%, respectively).

There were significant associations between SAM and other diseases. This study revealed that suspected measles was three time higher among children with SAM than others $(4.5 \% ; p<0.05)$. Many studies have shown that measles may cause malnutrition, and the nutritional status of children may also determine the severity of measles [25]. Diarrhea, fever, and cough rates were significantly higher among children with SAM in this study $(p<0.05)$. The risk of illness upsurged significantly with an increasing severity of malnutrition in children [26].

The reported vaccination coverage in this study was high $(>90 \%)$; however, the national immunization coverage reported by national authorities was estimated at $83 \%$ for DPT3 (Diphtheria, Tetanus and Pertussis) in 2017, and WHO/UNICEF estimated it at 68\% [27]. Immunization coverage is severely affected by the ongoing conflict. Immunization services are available in only $35 \%$ of functional health facilities in the county [28].

The deterioration of food security in Yemen is expected to continue as long as the conflict is ongoing, thus affecting household livelihoods and the general marketing situation. Food prices have sharply increased in local markets, which deprives the majority of this survey population who depend on the local market to get their daily food. In addition to high prices, other challenges include a reduction in family income from farming, fishing, or governmental salaries [29].

Approximately $30 \%$ of the study population depended on agriculture as their food source, particularly in Ibb. Approximately $11 \%$ depended on humanitarian assistance overall in Yemen, comprising $17 \%$ in the Sana'a governorate and $6 \%$ in the Ibb governorate. However, in June 2016, the 
report of the food security cluster revealed that $29 \%$ of the study population in Ibb was reached by humanitarian food assistance, and it was a much higher number (56\%) in the Sana'a governorate [30]. Currently, food insecurity is a major public health problem in Yemen, and it is having significant social implications as households have tried multiple coping mechanisms to address their hunger. Borrowing food was observed to be the first step to mitigate the adverse effect of food insecurity at the household level in Yemen. In Bangladesh, the majority of poor households primarily chose borrowing money to buy food and compromised on the quality and quantity of food [31]. Unfortunately, households in Yemen also chose among these tough options, including sending their children to live with other families.

This study has some limitations. There were (and still are) challenges to obtain reliable data from mothers or relatives of children, for example, with regard to history of measles and fever during the last ten days prior to this survey. Health staff depended on relatives to recall information regarding the vaccination status of children, which had a high probability of recall bias.

\section{Conclusions}

Malnutrition among children is a serious public health problem in Yemen, and the severity of acute malnutrition increases among children under two years. The majority of families in Yemen depend on food purchasing from the market, which is itself a disaster because of economic deterioration and lack of salaries. The question that needs further investigation is: Does humanitarian assistance have an impact in Yemen, and what is the extent of this impact? We recommend that the humanitarian community adopt alternative strategies to improve food security and nutrition status in Yemen. Income-generating projects to improve the resilience of the vulnerable Yemeni population is one of the recommendations.

Author Contributions: F.D. worked on study conceptualization, methodology, data analysis, and writing the manuscript. E.A.-F. participated in the methodology, investigation, editing, and review of the manuscript. O.I. participated in the methodology, investigation, and review the manuscript. L.A.-M. contributed in manuscript visualization, editing, and review. A.A.J. contributed in reviewing the manuscript and interpreting the results. N.N.N. analyzed, interpreted the results, edited, and reviewed. E.S. contributed in manuscript visualization, editing, and review. A.J. supervised, contributed in the manuscript writing and review, and gave final approval. All authors read and approved the final manuscript.

Acknowledgments: We express our gratitude to staff of the Governorate Health Offices in Sana'a and Ibb in Yemen for their efforts in conducting this field survey to provide the data and supporting the surveillance system. We acknowledge the financial support of Deutsche Forschungsgemeinschaft within the Open Access Publishing funding program and the Baden-Württemberg Ministry of Science, Research and the Arts, and Ruprecht-Karls-Universität Heidelberg.

Conflicts of Interest: The authors declare no conflict of interest.

\section{References}

1. Burki, T.K. Yemen's hunger crisis. Lancet 2012, 380, 637-638. [CrossRef]

2. Rethinking Yemen's Economy. Addressing Yemen's Most Critical Challenges: Practical Short-Term Recommendations. May 2017: Sana'a, Yemen. Available online: http://sanaacenter.org/wp-content/ uploads/2017/06/Rethinking-Yemen\%E2\%80\%99s-Economy-policy-brief-1.pdf (accessed on 17 February 2018).

3. Fink, M.D. Naval Blockade and the Humanitarian Crisis in Yemen. Neth. Int. Law Rev. 2017, 64, $291-307$. [CrossRef]

4. FAO. Situation Report; United Nation's Food and Agriculture Organization: Sana'a, Yemen, February 2017.

5. FAO; FSTS/MoPIC. Integrated Food Security Phase Classification (IPC); United Nation's Food and Agriculture Organization: Sana'a, Yemen, 2017.

6. MoPHP; CSO. Yemen National Health and Demographic Survey; Ministry of Public Health and Population, and Central Statistical Organization (CSO): Sana'a, Yemen, 2013.

7. OCHA. Humanitarian Needs Overview (HNO); United Nations Office for the Coordination of Humanitarian Affairs: Sana'a, Yemen, 2018. 
8. Protection Cluster Yemen, Task Force on Population Movemnt (TFPM). 14th Report Executive Summary; IOM and UNHCR: Sana'a, Yemen, 2017.

9. OCHA. Yemen Humanitarian Response Plan; United Nations Office for the Coordination of Humanitarian Affairs: Sana'a, Yemen, 2017.

10. UNICEF. Yemen Crisis: The Impact of Violence and Conflict on Yemen and Its Children; UNICEF: Sana'a, Yemen, 2016.

11. Chisti, M.J.; Tebruegge, M.; La Vincente, S.; Graham, S.M.; Duke, T. Pneumonia in severely malnourished children in developing countries-Mortality risk, aetiology and validity of WHO clinical signs: A systematic review. Trop Med Int. Health 2009, 14, 1173-1189. [CrossRef] [PubMed]

12. World Health Organization (WHO). Child and Adolescent Health-Yemen. 2015. Available online: http: //www.emro.who.int/child-adolescent-health/data-statistics/yemen.html (accessed on 2 December 2017).

13. World Health Organization (WHO). Children: Reducing Mortality. 2016. Available online: http://www.who. int/mediacentre/factsheets/fs178/en/ (accessed on 2 December 2017).

14. Bilukha, O.; Leidman, E. Concordance between the estimates of wasting measured by weight-for-height and by mid-upper arm circumference for classification of severity of nutrition crisis: analysis of population-representative surveys from humanitarian settings. BMC Nutr. 2018, 4, 24. [CrossRef]

15. Ziolkovska, A. Nutrition Cluster Bulletin: Overview of the Nutrition Situation as of 31 March 2017; UNICEF: Sana'a, Yemen, 2017.

16. UNICEF; MOPH\&P. Nutrition and Mortality Survey Report Sana'a Governorate, (SMART); UNICEF: Sana'a, Yemen, 2016.

17. WFP; FAO; UNICEF. Emergency Food Security and Nutrition Assessment (EFSNA); Food Security and Agriculture Cluster: Sana'a, Yemen, 2016.

18. UNICEF; MOPH\&P. Nutrition and Mortality Survey Report Ibb Governorate (SMART); UNICEF: Sana'a, Yemen, 2017.

19. FEWS. Improved Humanitarian access and Trade Support Needed to Limit Famine Risk; Famine Early Warning System Network: Sana'a, Yemen, 2017.

20. FAO; FSTS/MoPIC. Integrated Food Security Phase Classification (IPC); United Nation's Food and Agriculture Organization: Sana'a, Yemen, 2018.

21. Kumar, D.; Goel, N.K.; Mittal, P.C.; Misra, P. Influence of infant-feeding practices on nutritional status of under-five children. Indian J. Pediatr. 2006, 73, 417-421. [CrossRef] [PubMed]

22. Kapur, D.; Sharma, S.; Agarwal, K.N. Dietary intake and growth pattern of children 9-36 months of age in an urban slum in Delhi. Indian Pediatr. 2005, 42, 351-356. [PubMed]

23. WHO. Infant and Young Child Feeding. 2018. Available online: https://www.who.int/news-room/fact-sheets/ detail/infant-and-young-child-feeding (accessed on 25 May 2019).

24. Amsalu, S.; Tigabu, Z. Risk factors for ever acute malnutrition inchildren under the age of five: A case-control study. Ethiop. J. Health Dev. 2008, 22, 21-25. [CrossRef]

25. Bhaskaram, P. Measles \& malnutrition. Indian J. Med. Res. 1995, 102, 195-199. [PubMed]

26. Olwedo, M.; Mworozi, E.; Bachou, H.; Orach, C. Factors associated with malnutrition among children in internally displaced person's camps, northern Uganda. Afr. Health Sci. 2008, 8, 18.

27. GAVI. Yemen. 2017. Available online: https://www.gavi.org/country/yemen/ (accessed on 25 May 2019).

28. Dureab, F.; Al-Sakkaf, M.; Ismail, O.; Kuunibe, N.; Krisam, J.; Müller, O.; Jahn, A. Diphtheria outbreak in Yemen: The impact of conflict on a fragile health system. Conflict Health 2019, 13, 19. [CrossRef] [PubMed]

29. FEWS. Yemen Alert; Famine Early Warning System Network: Sana'a, Yemen, January 2017.

30. WFP; VAM-Team. Emergency Food Assistance-Total Number of Beneficiaries Targeted/Reached by the Food Security and Agriculture Cluster Partners; Food Security Cluster: Sana'a, Yemen, 2016.

31. Farzana, F.; Rahman, A.; Sultana, S.; Raihan, M.; Haque, M.; Waid, J.; Choudhury, N.; Ahmed, T. Coping strategies related to food insecurity at the household level in Bangladesh. PLoS ONE 2017, 12, e0171411. [CrossRef] [PubMed]

(C) 2019 by the authors. Licensee MDPI, Basel, Switzerland. This article is an open access article distributed under the terms and conditions of the Creative Commons Attribution (CC BY) license (http://creativecommons.org/licenses/by/4.0/). 